Published in Experimental Neurology 186: 78-88, 2004

\title{
Ectopic parvalbumin expression in mouse forebrain neurons increases excitotoxic injury provoked by ibotenic acid injection into the striatum
}

\author{
Walter Maetzler, ${ }^{\mathrm{a}}$ Cordula Nitsch, ${ }^{\mathrm{a}, *}$ Kerstin Bendfeldt, ${ }^{\mathrm{a}}$ Peter Racay, ${ }^{\mathrm{b}}$ \\ Florence Vollenweider, ${ }^{\mathrm{a}}$ and Beat Schwaller ${ }^{\mathrm{b}}$ \\ ${ }^{a}$ Section of Neuroanatomy, Institute of Anatomy, University of Basel, 4056 Basel, Switzerland \\ ${ }^{\mathrm{b}}$ Division of Histology, Department of Medicine, University of Fribourg, Switzerland
}

Received 20 June 2003; revised 11 September 2003; accepted 25 September 2003

\begin{abstract}
A neuroprotective role for $\mathrm{Ca}^{2+}$-binding proteins in neurodegenerative conditions ranging from ischemia to Alzheimer's disease has been suggested in several studies. A key phenomenon in neurodegeneration is the $\mathrm{Ca}^{2+}$-mediated excitotoxicity brought about by the neurotransmitter glutamate. To evaluate the relative ability to resist excitotoxicity of neurons containing the slow-onset $\mathrm{Ca}^{2+}$-binding protein parvalbumin (PV), we injected the glutamate agonist ibotenic acid (IBO) into the striatum of adult mice ectopically expressing PV in neurons. Striatal ibotenic acid injection results in local nerve cell loss and reactive astrogliosis. Light microscopic evaluation, carried out after a delay of 2 and 4 weeks, reveals an enlarged and accelerated neurodegenerative process in mice ectopically expressing neuronal PV. Thus, PV is not neuroprotective, it rather enhances nerve cell death. This result implicates that the increase in cytosolic $\mathrm{Ca}^{2+}$-buffering capacity in the transgenic mice impairs other systems involved in $\mathrm{Ca}^{2+}$ sequestration. In addition, ultrastructural morphometric analysis shows that in neurons the mitochondrial volume is reduced in mice ectopically expressing neuronal PV. This is paralleled by a reduction in the amount of the mitochondrial marker enzyme cytochrome $c$ oxidase subunit I (COXI). We conclude that alterations in the $\mathrm{Ca}^{2+}$ homeostasis present in mice ectopically expressing neuronal PV are more deleterious under excitotoxic stress and largely outweigh the potential benefits of an increased $\mathrm{Ca}^{2+}$-buffering capacity resulting from $\mathrm{PV}$.
\end{abstract}

Keywords: Neurodegeneration; Excitotoxicity; $\mathrm{Ca}^{2+}$-binding proteins; $\mathrm{Ca}^{2+}$ sequestration; Glial fibrillary acidic protein; Mitochondria

\section{Introduction}

Excitatory amino acid neurotransmitters play an important role in acute and chronic diseases in the CNS, including stroke, Huntington's, Alzheimer's and Parkinson's disease (for reviews, see DiFiglia, 1990; Dirnagl et al., 1999; Hossmann, 1994; Lipton and Rosenberg, 1994). The neurotoxicity of these substances can be considered as an exaggeration of the physiological action of glutamate as a

Abbreviations: AMPA, alpha-amino-3-hydroxy-5-methyl-4-isoxazolepropionic acid; BAPTA, 1,2 bis-(2-aminophenoxy)ethane- $N, N, N^{\prime}, N^{\prime}$-tetraacetic acid; COXI, cytochrome $c$ oxidase subunit I; GABA, $\gamma$ aminobutyrate; GFAP, glial fibrillary acidic protein; IBO, ibotenic acid; KO, knockout; NMDA, $N$-methyl-D-aspartate; PV, parvalbumin; WT, wildtype mice.

* Corresponding author. Section of Neuroanatomy, Institute of Anatomy, University of Basel, Pestalozzistrasse 20, 4056 Basel, Switzerland. Fax: +41-61-267-39-59.

E-mail address: cordula.nitsch@unibas.ch (C. Nitsch). neurotransmitter, that is, binding to its postsynaptic receptors. The result is an overstimulation of $N$-methyl-D-aspartate (NMDA), alpha-amino-3-hydroxy-5-methyl-4-isoxazolepropionic acid (AMPA) and kainate receptors (Weiss and Sensi, 2000), with consequent influx of $\mathrm{Na}^{+}$and $\mathrm{Ca}^{2+}$ ions through the channels gated by these receptors. Excessive $\mathrm{Ca}^{2+}$ influx is mediated directly and predominantely by NMDA receptors, which gate channels that are highly permeable to $\mathrm{Ca}^{2+}$, but is also triggered secondarily by $\mathrm{Na}^{+}$influx through AMPA and kainate receptors, as well as via activation of voltage-gated $\mathrm{Ca}^{2+}$ channels and reverse operation of the $\mathrm{Na}^{+} / \mathrm{Ca}^{2+}$ exchanger. Further, the glutamate-mediated activation of metabotropic receptors induces release of $\mathrm{Ca}^{2+}$ from intracellular stores. Together, this results in elevated intracellular $\mathrm{Ca}^{2+}$ concentrations (Choi, 1988 ; 1995) with serious consequences such as necrosis and apoptosis (Lee et al., 1999). Stimulation of catabolic enzymes and induction of $\mathrm{Ca}^{2+}$ sequestration in the mitochondrial matrix, which leads to a collapse of mitochondrial 
membrane potential, have been described (Schinder et al., 1996). Blockade of glutamate receptors prevents most of the $\mathrm{Ca}^{2+}$ influx and neuronal cell death induced by glutamate exposure (Simon et al., 1984; Turski et al., 1998).

Parvalbumin (PV) is a cytosolic $\mathrm{Ca}^{2+}$ buffer expressed in GABAergic ( $\gamma$-aminobutyrate) neurons in the cerebral and cerebellar cortex and is present in numerous nuclei of the brain (Andressen et al., 1993; Hontanilla et al., 1998). In rodent striatum, PV-containing neurons are rare and occur mainly in the peripheral regions of striosomes where they participate in linking the two striatal compartments (Kita et al., 1990).

The correlation between PV and excitotoxic cell death is still unclear. On the one hand, a neuroprotective role for PV has been described in hippocampal interneurons surviving delayed ischemic cell death after a transient bilateral occlusion of the carotid arteries (Nitsch et al., 1989). PV-containing neurons also exhibit a higher survival rate in the human epileptic hippocampus (Sloviter et al., 1991), and recently, a protective effect of $\mathrm{PV}$ on excitotoxic motor neuron death has been observed (Van Den Bosch et al., 2002). On the other hand, PV-containing neurons are supposed to be selectively vulnerable in Alzheimer's disease (Solodkin et al., 1996) and not to be protected in some forms of epilepsy (Bouilleret et al., 2000). In an in vitro model, a HSV-1 vector-driven expression of PV in cultured cortical neurons resulted in an enhancement of NMDA neurotoxicity (Hartley et al., 1996).

To determine the role of PV in excitotoxicity, we injected ibotenic acid (IBO) in the striatum of mice ectopically expressing neuronal PV. IBO is an agonist of glutamate (Zorumski et al., 1989). It induces neurodegeneration by activation of the NMDA receptors (Marret et al., 1996) and by coactivation of the metabotropic glutamate receptors, mediating the release of $\mathrm{Ca}^{2+}$ from intracellular stores. This results in well-demarcated lesions (Inglis and Semba, 1997), which can be easily compared in wildtype mice (WT) and transgenic mice. We show here that neurons expressing PV ectopically are more vulnerable against excitotoxic stress.

\section{Materials and methods}

Mice

Transgenic mice with a C57BL/6J background, 20-34 g in weight $(n=18)$, ectopically expressing PV under the control of the pan-neuronal Thy-1 promoter were used (Van Den Bosch et al., 2002). In the CNS, the Thy-1 promoter driving the expression of PV has been previously shown to be active in neurons (Andra et al., 1996; Caroni, 1997; Wisden et al., 2002), but expression levels can vary considerably among different neuron types. Mice expressing the highest level of PV were selected for this study. As control strain, C57BL/6J mice, $20-31 \mathrm{~g}$ in weight $(n=18)$ were used. At the day of injection, the age of the mice ranged from 95 to 296 days. No sex- or age-related variations concerning the following investigations have been observed. For quantitative analysis of mitochondria, 8 transgenic mice and 10 WT were used, in addition. All animal experiments were performed with permission of the local animal care committee and according to the present Swiss law.

\section{Determination of genotype}

Detection of transgenic mice was carried out by PCR on genomic mouse tail DNA as described previously (Castillo et al., 1995). Briefly, rat-specific PV cDNA primers (OL1 $5^{\prime}$-TCCAGATGGTGG-GCCTGAAGAAAAAGAGTG-3' and OL2, 5'-GTCCCCGTCCTTGTCTCCAGCAGCCATC $-3^{\prime}$ as the $5^{\prime}$ and $3^{\prime}$ primers) and, as a template, $1 \mu \mathrm{g}$ of genomic DNA were used. A PCR amplicon of $194 \mathrm{bp}$ was produced. In addition, PV immunohistochemistry was carried out to confirm the results obtained by PCR.

\section{Surgical procedure}

Under combined anesthesia with ketaminum (Ketamin ${ }^{\circledR}$, $0.1 \mathrm{~g} / \mathrm{kg}$ ip), xylazinum $\left(\mathrm{Narcoxyl}^{\circledR}, 0.02 \mathrm{~g} / \mathrm{kg}\right.$ ip) and atropin (Atropin, $0.05 \mathrm{mg} / \mathrm{kg}$ ip), mice were placed in a stereotaxic apparatus. Ibotenic acid (IBO; Sigma, $0.4 \mu \mathrm{g}$ in $0.4 \mu \mathrm{l}$ buffered saline) was injected with a glass capillary glued onto a Hamilton microsyringe at the coordinates AP + $4.8 \mathrm{~mm}, \mathrm{~L} 2.1 \mathrm{~mm}$ and V $2.5 \mathrm{~mm}$ above ear zero plane according to the atlas of Franklin and Paxinos (1997). Injection time was $10 \mathrm{~min}$, and further 10-15 min elapsed before the needle was withdrawn and the wound closed. After the effects of anesthesia had subsided, most of the mice showed a marked tendency to rotate to the side contralateral to the injection, some of them rotated ipsilateral, a behavior which correlates with the exact localization of the excitotoxin injection. Sham animals (two each, of WT and of the transgenic ones) were injected with the same amount of $0.9 \% \mathrm{NaCl}$ and showed no rotation behavior.

\section{Tissue preparation}

After a recovery period of 2 weeks (9 transgenic, 6 WT) and 4 weeks ( 7 transgenic, $10 \mathrm{WT}$ ), the animals were deeply anesthetized with pentobarbital (Vetanarcol ${ }^{\circledR}, 0.04 \mathrm{~g} / \mathrm{kg}$ ip) and transcardially perfused first with $4 \%$ paraformaldehyde and $0.2 \%$ glutaraldehyde in $0.1 \mathrm{M}$ phosphate buffer, $\mathrm{pH} 7.4$, followed by the same fixative without glutaraldehyde. The dissected brains were immersed in fixative overnight.

\section{Histology and immunohistochemistry}

Serial sagittal $40-\mu \mathrm{m}$ sections were cut with a vibratome and collected in cold Tris phosphate buffer (TBS, $0.05 \mathrm{M}$ ). To measure the extent of nerve cell death and the position of the needle, every fifth section was mounted on glycerincoated slides and stained with $0.5 \%$ cresyl violet. 
To evaluate PV immunoreactivity and astrocytic reaction, immunohistochemistry on every fifth section was performed as already described (Nitsch et al., 1995). In brief, free-floating sections were treated with $1 \% \mathrm{NaBH}_{4}$ for
$10 \mathrm{~min}$, washed thoroughly and solubilized with $0.4 \%$ Triton X-100 in $0.05 \mathrm{M}$ Tris-buffered saline (TBS) for 90 min. Nonspecific binding was blocked with normal serum (horse or goat serum) for $2 \mathrm{~h}$, then sections were incubated
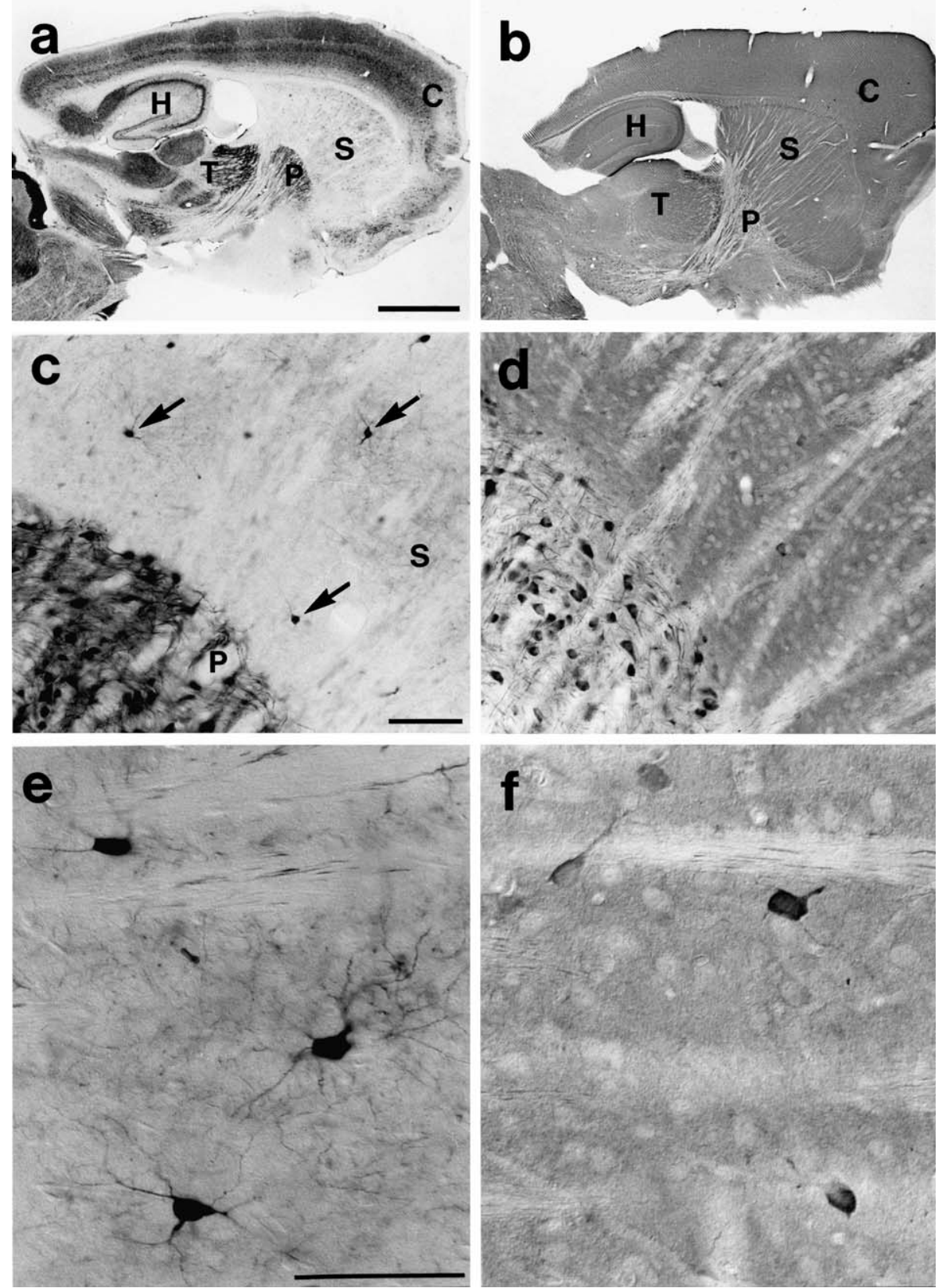

Fig. 1. Parvalbumin (PV) immunohistochemistry shown in parasagittal brain sections of a wildtype (left panel) and a mouse ectopically expressing PV in its neurons (right panel). (a) In wildtype, PV expression is pronounced in interneurons, mainly in the neocortex (C), hippocampus (H), in neurons of the globus pallidus (P) and the thalamus (T), while in the striatum (S), only few PV-containing interneurons are observable. (b) An increased homogenous PV immunoreactivity throughout the gray matter of the whole brain is characteristic for the transgenic mouse. (c) Staining is absent in the wildtype striatum (S) except for a few clearly marked interneurons (arrows), in contrast to the globus pallidus (P) with its many PV-positive neurons. (d) The same area in the transgenic mouse shows a dense PV immunoreactivity in the striatal neuropil, only omitting the fiber tracts of the internal capsule. Although the staining in globus pallidus tends to appear weaker than in wildtype (c), PV amount in pallidal neurons is probably similar in both strains, suggesting that the contrast to the neighboring striatum is responsible for this erroneous perception. (e) Single PV immunoreactive interneurons of the striatum with their locally branching dendrites. (f) Dense PV immunoreactivity in mice ectopically expressing PV in their neurons blurs the dendritic arborization of the PV-containing interneurons. Perikarya of PV-immunoreactive interneurons exhibit a stronger signal than perikarya in which PV has been up-regulated by the transgene. Scale bar for $\mathrm{a}, \mathrm{b}=$ $1 \mathrm{~mm}, \mathrm{c}-\mathrm{f}=100 \mu \mathrm{m}$. 
with antibodies against PV (monoclonal PV235, 1:20,000; Swant, Bellinzona, Switzerland) or glial fibrillary acidic protein (GFAP, 1:1000; Sigma) for $48 \mathrm{~h}$ at room temperature. Biotinylated horse anti-mouse (1:200; Vector) or goat anti-rabbit IgG (1:100; Antibodies Inc.), and the avidinbiotin complex (Vector) were applied for $90 \mathrm{~min}$ each.
Immunoreaction was visualized with $0.05 \%$ diaminobenzidine and $0.1 \% \mathrm{H}_{2} \mathrm{O}_{2}$ in TBS.

All sections were mounted in series from lateral to medial on coated slides, dehydrated in graded ethanol, cleared with xylol and coverslipped in Eukitt (Kindler, Freiburg, Germany).
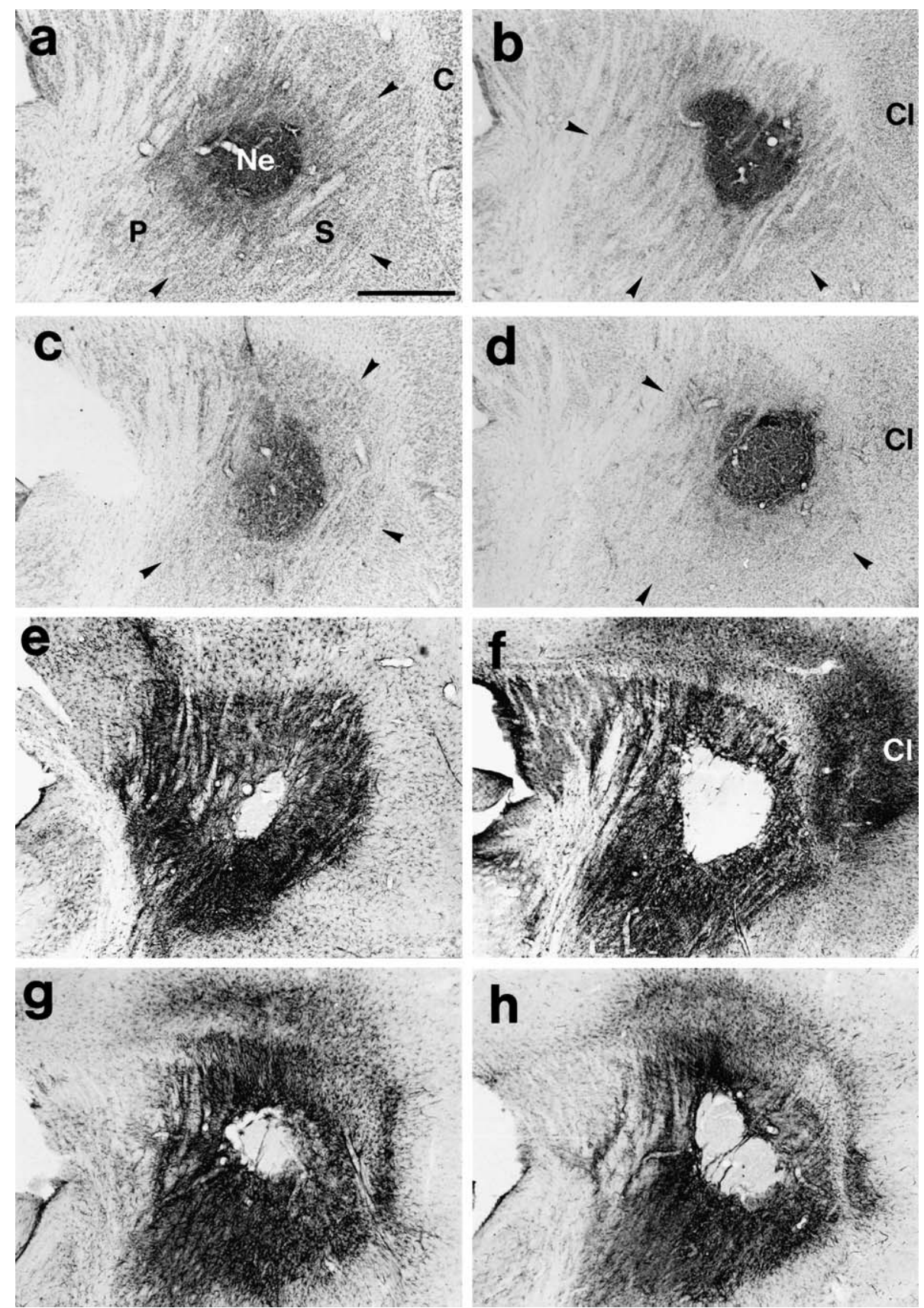

Fig. 2. (a-d) Ibotenate-induced lesions in wildtype (left panel) and mice ectopically expressing PV in their neurons (right panel) visualized in cresyl-stained sections, obtained after 2 weeks $(\mathrm{a}, \mathrm{b})$ and after 4 weeks $(\mathrm{c}, \mathrm{d})$. A small necrotic center (Ne), where the capillary tip has been positioned and where all tissue elements are destroyed, is surrounded by a large zone of nerve cell loss (arrowheads). Most of the affected area is striatal tissue (S), but also parts of the globus pallidus $(\mathrm{P})$ are affected. Cortex $(\mathrm{C})$. (e-f) Ibotenate-induced lesions visualized in GFAP immunohistochemistry after 2 (e, $\mathrm{f})$ and 4 weeks survival time ( $\mathrm{g}$, h). Note the larger extent of astrocytosis compared to neuronal cell loss in general, but also the pronounced involvement of cortical tissue (Cl) in transgenic mice $(\mathrm{f}, \mathrm{h})$ and the strongly reduced extent of GFAP immunoreactivity in transgenic mice after 4 weeks survival time compared to the extent of activated GFAP after 2 weeks (f, h). Scale bar $=500 \mu \mathrm{m}$. 


\section{Quantitative Western blot analysis}

A membrane protein fraction was prepared by homogenization of forebrain tissue in homogenization buffer [10 $\mathrm{mM}$ Tris- $\mathrm{HCl}, 1 \mathrm{mM}$ EDTA, $\mathrm{pH}$ 7.4, containing one tablet of protease inhibitor cocktail (Roche; cat. nr. 1873580) per $10 \mathrm{ml}$ of buffer] using a Polytron homogenizer. Membranes were sedimented by centrifugation at $30,000 \times g$ for $30 \mathrm{~min}$, resuspended in homogenization buffer, once more sedimented under the same conditions and then resuspended in $1 \%$ SDS. Membrane proteins were solubilized by addition of $10 \%$ SDS to a final concentration of $5.5 \%$. Protein concentration was determined by the protein Dc assay kit (Bio-Rad). Proteins (50 $\mu \mathrm{g})$ were separated by polyacrylamide gel electrophoresis (SDS-PAGE) and transferred on nitrocellulose membranes using a semidry transfer protocol. The membranes were assayed for even protein load and possible transfer artifacts by staining with Ponceau red solution. After blocking with $10 \%$ solution of nonfat milk in TBS-T buffer (TBS with addition of $0.05 \%$ of Tween 20), membranes were incubated with primary antibodies against cytochrome $c$ oxidase subunit I (COXI; $0.5 \mu \mathrm{g}$ / ml, ID6-E1-A8, $\operatorname{IgG}_{2 \mathrm{a}, \mathrm{\kappa}}$, Molecular Probes, Leiden, Netherlands, cat. A-6403) using a modified protocol according to Capaldi et al. (1995). Antibodies were diluted in TBS$\mathrm{T}$ solution containing $1 \%$ of protease-free bovine serum albumin. Incubation of membranes with primary antibod- ies was followed by extensive washing in TBS-T and subsequently by incubation of membranes with appropriate secondary biotinylated antibodies (1:10,000; Vector). After extensive washing, membranes were incubated with avidin-biotin-conjugated peroxidase (Vector) solution in TBS-T, washed again and the bands corresponding to COXI were visualized. The subunit I-specific band of approximately $60 \mathrm{kDa}$ (theoretical $M_{\mathrm{r}}: 57 \mathrm{kDa}$ ) was used for the quantitative analysis using the Molecular Imager hardware and software from the same manufacturer. Exposition on the phosphoimager screen was $15 \mathrm{~min}$. Linearity of the COXI signal was checked by analyzing different amounts of muscle membrane proteins and different exposition times.

\section{Morphometric analysis of neuronal mitochondria}

Untreated striatal tissue from unstained vibratome sections were processed for transmission electron microscopy. The sections were incubated with $0.1 \%$ osmium tetroxide $\left(\mathrm{OsO}_{4}\right.$; Serva), dehydrated until $70 \%$ ethanol, incubated with $1 \%$ uranyl acetate (Merck, Darmstadt, Germany) in $70 \%$ ethanol, dehydrated until $100 \%$ ethanol, transferred in propylene oxide (Merck) and embedded in a plastic resin (Epon; Serva). Ultrathin sections were analyzed under the electron microscope (Philips CM 10 Digital). Eight neurons were randomly selected in one grid per animal, and three digital micrographs (analySIS ${ }^{\circledR}$ ) per neuron were
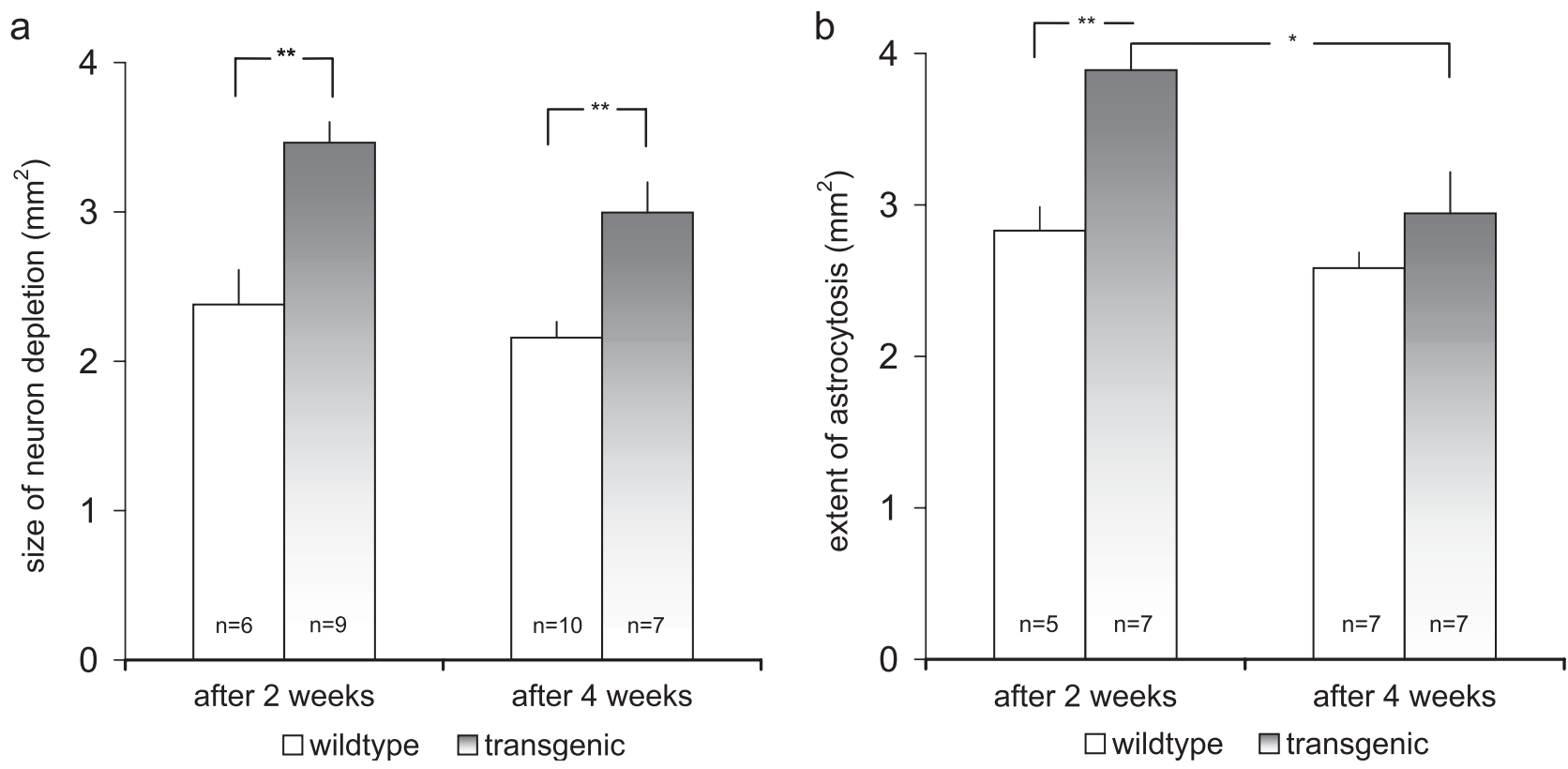

Fig. 3. (a) Size of the neuron-depleted area in wildtype mice and in mice ectopically expressing PV in their neurons: transgenic mice show after 2 weeks ( 3.46 versus $2.38 \mathrm{~mm}^{2} ; P=0.003$ ) as well as after 4 weeks ( 3.00 versus $2.16 \mathrm{~mm}^{2} ; P=0.003$ ) a larger extent of the neuron-depleted area as compared to wildtype. (b) Extent of astrocytosis in wildtype mice and in mice ectopically expressing PV in their neurons: astrocytosis is more pronounced in transgenic mice than in wildtype mice after 2 weeks ( 3.89 versus $\left.2.83 \mathrm{~mm}^{2} ; P=0.001\right)$, this difference is no longer significant after 4 weeks $\left(2.94\right.$ versus $\left.2.58 \mathrm{~mm}^{2} ; P=0.25\right)$. The reduction in the extent of GFAP immunoreactivity from 2 to 4 weeks is significant in the transgenic strain $(P=0.02)$ but not in wildtype mice $(P=0.23)$. (a, b) GFAP-stained areas tend to be larger than the corresponding neuron-depleted areas after 2 weeks in both mouse strains $(P=0.11$ in transgenic, $P=0.16$ in wildtype), this tendency has disappeared in transgenic mice after 4 weeks $(P=0.88)$, but has become significant in wildtype $(P=0.03)$. 
taken out of the perikaryon at positions 12,4 and 8 o'clock in direct contact to the nucleus at a primary magnification of $\times 11,000$.

\section{Data analysis}

For histological measurements, the section with the largest lesion, often exhibiting the needle tract, was selected in cresyl and GFAP staining (laterality $=2.00-2.20$ $\mathrm{mm}$ ), and size of the striatum, the central necrosis, the neuron-depleted area and the extent of astrocytosis were analyzed with Leica Image Scale system. For analysis of the Western blot, the bands corresponding to COXI were quantified by the Molecular Imager (Bio-Rad) using the ECL chemoluminescence method (Pierce). The area of neurons occupied by mitochondria was determined with Image-Pro ${ }^{\circledR}$ software.
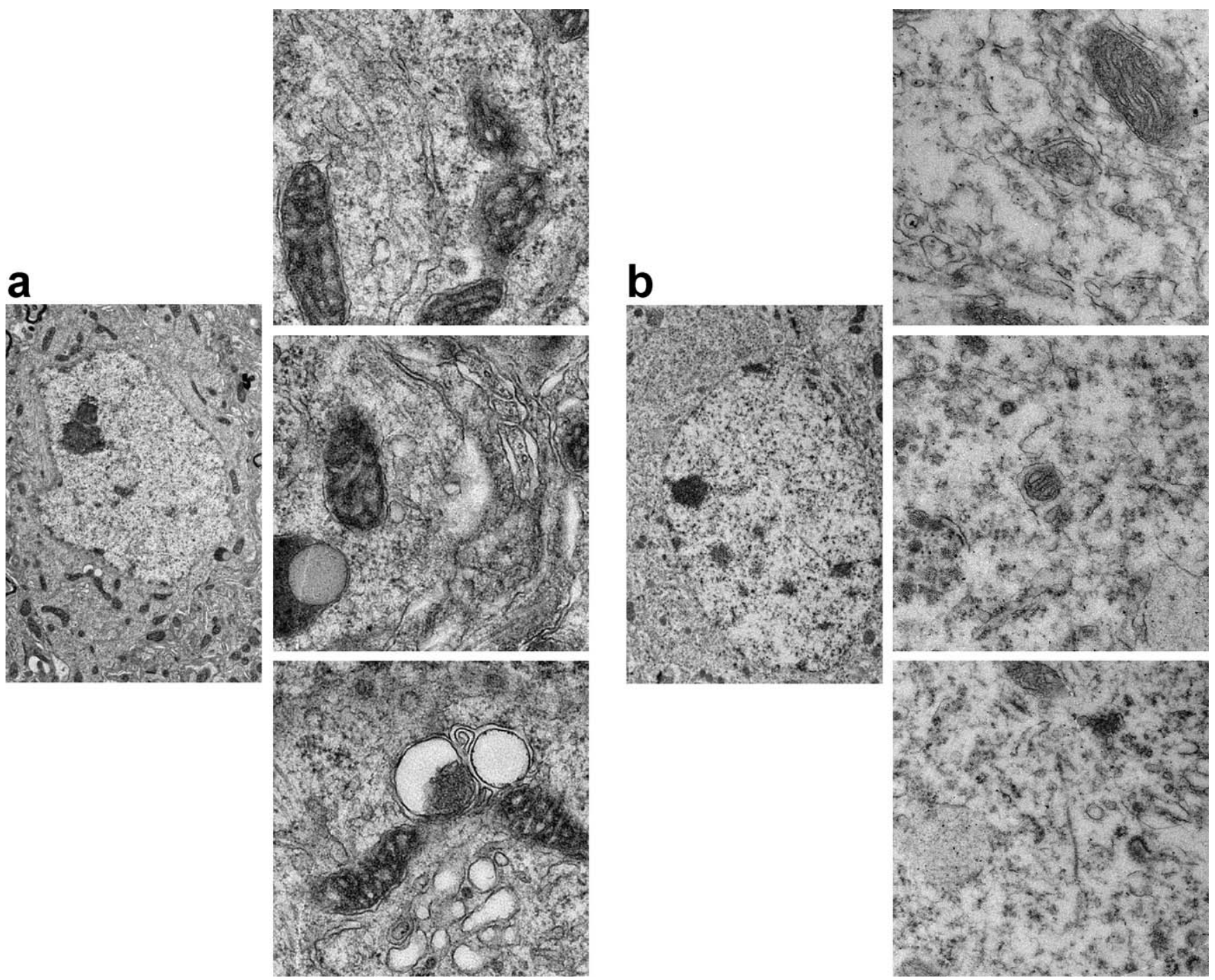

Phenotype of transgenic mice is distinguishable from WT with respect to $P V$ expression

Transgenic mice were found to have no apparent phenotype when kept under standard housing conditions. In PV immunohistochemistry, there was an increased PV immunoreactivity throughout the brain since all neurons express PV. Nevertheless, the characteristic pattern of PV distribu-

Fig. 4. Electron micrographs of a wildtype striatal neuron (left panel) and a neuron ectopically expressing PV (right panel) revealed more fractional mitochondrial area in wildtype neurons. Measurements were performed in digital micrographs taken at a primary magnification of $\times 11,000$ in the perikaryal field directly adjacent to the nucleus at 12,4 , and 8 o'clock irrespective of the presence or absence of mitochondria (small figures from top to bottom). 
tion was discernible: the expression level in neurons normally expressing PV (Celio, 1990) was still obviously higher than in all other neurons, for example, interneurons in the neocortex, the hippocampus (Nitsch et al., 1995), the reticulothalamic nucleus (compare Figs. 1a, b) and the cerebellum (not shown). In wildtype striatum with its low number of PV-containing interneurons (Figs. 1c, e), staining is virtually absent. In contrast, in striatum of transgenic mice, presence of PV in all striatal neurons results in a homogenous staining that blurs the dendritic arborizations of the PV-containing interneurons (Figs. 1d, f).

Injection of ibotenic acid in the mouse striatum provokes a central necrosis surrounded by a drop-shaped neuron-depleted zone

The histological aspect of the IBO-induced lesion was similar to previous studies (Schwarcz et al., 1979). In both WT and mice ectopically expressing neuronal PV, striatal injection of IBO provoked a globular or drop-shaped neurondepleted zone (Figs. 2a-d) and a zone of activated glia (Figs. $2 \mathrm{e}-\mathrm{h}$ ), surrounding a small globular-shaped central necrosis. As a typical feature of IBO, the border of the neurondepleted area to healthy tissue was abrupt. Since the lesion was often about as large as the whole striatum, some animals were injured also in flanking cortical areas (Figs. 2b, d). In sham animals, the needle tract was identifiable in all stainings, but no other alteration of tissue (necrosis and/or neuron depletion) was detectable (not shown).

Vulnerability of neurons ectopically expressing $P V$ to excitotoxic stress is enhanced

Quantitative analyses revealed that sizes of necrotic zones between transgenic mice and WT did not differ (after 2 weeks 0.32 versus $0.15 \mathrm{~mm}^{2} ; P=0.11$, after 4 weeks 0.23 versus $\left.0.20 \mathrm{~mm}^{2} ; P=0.75\right)$. However, the neuron-depleted area in mice ectopically expressing neuronal PV was larger than in WT, $45 \%$ after 2 weeks and $39 \%$ after 4 weeks (Fig. 3a). The size of the striatum shrunk in both strains from 2 to 4 weeks by around $25 \%(P<0.001$, data not shown). As there is a concentration gradient of IBO from the center of the injection to the periphery, it can be concluded that neurons ectopically expressing PV have a lower threshold level of being damaged through excitotoxic stress.

\section{Astrocytic reaction to excitotoxic stress is enhanced in mice ectopically expressing neuronal $P V$}

Astrocytic reaction to excitotoxic stress was evaluated by GFAP immunoreactivity. This astroglial marker was upregulated near and in the neuron-depleted zone in both mouse strains.

After 2 weeks, astrocytosis was 37\% more widespread in transgenic mice than in WT. Both mouse strains showed a pronounced GFAP immunoreactivity in the outer border of

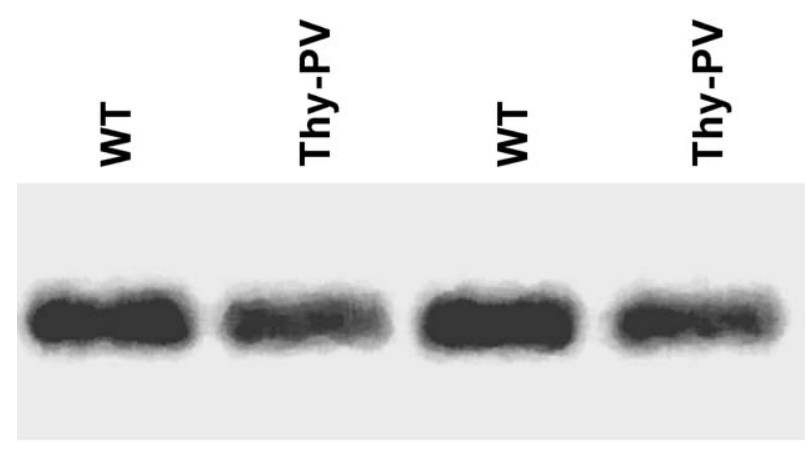

Fig. 5. Semiquantitative Western blot analysis of cytochrome $c$ oxidase subunit $I$ in forebrain tissue revealed a weaker signal in samples of mice ectopically expressing PV in their neurons (Thy-PV) compared to samples from wildtype (WT) mice.

the neuron-depleted area reproducing the inward migration of activated astrocytes from the periphery to the center of a lesion over time (Dusart et al., 1991). The necrotic core was devoid of reactive astrocytes (Figs. 2e-f).

After 4 weeks, the difference in extent of astrocytosis between the two strains was no longer significant. GFAP was equally distributed in the whole lesioned area, a partial astroglial reinvasion of the central necrosis was observed in a few cases (Figs. $2 \mathrm{~g}-\mathrm{h}$ ). The reduction in extent of GFAP immunoreactivity from 2 to 4 weeks was significant in mice ectopically expressing neuronal PV but not in WT (Fig. 3b).

Fractional mitochondrial area of neurons ectopically expressing $P V$ is decreased

To compare the mitochondrial fraction of neurons ectopically expressing PV with wildtype neurons, morphometric analyses were carried out on electron microscopical sections obtained from striatal neurons of untreated mice ectopically expressing neuronal PV and untreated WT (Fig. 4). The fractional mitochondrial area in perikarya of Thy-PV neurons was massively reduced to nearly half compared to values obtained for WT $(16.71 \%, n=4$ versus $30.28 \%, n=$ 6; $P=0.0003)$.

Semiquantitative Western blot analysis of the mitochondrial protein COXI (Chen et al., 2001) was done in the forebrain of mice and confirmed our morphometric mitochondria data. In samples of mice ectopically expressing neuronal PV, the signal for COXI was weaker as compared to that from WT (Fig. 5). Quantitative analysis of the Western blot signals with the help of a phosphoimager system showed a down-regulation of COXI by approximately $15 \%$ in the forebrain of transgenic mice (3.39 versus 4.04 arbitrary units, $P<0.005$ ).

\section{Discussion}

In this study, we demonstrate that the mouse striatum and adjacent cortex when ectopically expressing neuronal PV are 
more susceptible to IBO-induced excitotoxic injury. Further, ectopically expressed neuronal PV accelerates the progression of the pathologic process.

Excitotoxic cell death within the central nervous system induced by prolonged exposure to glutamate or glutamate agonists (e.g. IBO, NMDA) is closely linked to an exaggerated influx of $\mathrm{Ca}^{2+}$ in neurons often described as " $\mathrm{Ca}^{2+}$ overload". This type of cell death is regularly studied as a model of stroke mimicking the situation in ischemic brain, where glutamate accumulation to high concentrations is observed. The changes in the temporal pattern of the intracellular $\mathrm{Ca}^{2+}$ concentration $\left[\mathrm{Ca}^{2+}\right]_{\mathrm{i}}$ following glutamate application are remarkably constant in most models: an initial transient $\left[\mathrm{Ca}^{2+}\right]_{\mathrm{i}}$ rise, staying at a plateau for extended periods or with an incomplete recovery towards baseline (e.g. D'Orlando et al., 2001). For a long time, the hypothesis has been that addition of intracellular $\mathrm{Ca}^{2+}$ buffers such as PV or calbindin D-28k (CB) may confer a neuroprotective role in these models (Heizmann and Braun, 1992). While initial investigations mainly reported on a correlation of preferentially surviving neuronal populations and specific $\mathrm{Ca}^{2+}$ buffers, as discussed in D'Orlando et al. $(2001,2002)$, more recent studies have directly addressed the question of neurodegeneration. Systems in vitro or in vivo, where expression levels of CaBPs were directly manipulated, include transfected cell lines or transgenic animals with either deletions of $\mathrm{CaBP}$ genes or ectopically expressing CaBPs (reviewed in Schwaller et al., 2002).

Results on a neuroprotective role of PV are extremely heterogenous and examples discussed here are limited to the effects of PV on glutamate- or glutamate agonist-induced excitotoxicity and in amyotrophic lateral sclerosis (ALS). For the latter studies, two groups made use of transgenic mice either ectopically expressing PV under the control of the rat calmodulin II (CaMII) (Beers et al., 2001) or the Thy-1 promoter (Van Den Bosch et al., 2002) to assess whether increasing the $\mathrm{Ca}^{2+}$-buffering capacity of motoneurons may protect them from excitotoxic cell death. Motoneurons are considered to be particularly susceptible to $\mathrm{Ca}^{2+}$-mediated glutamate toxicity due to the lack of a substantial amount of any CaBP (Shaw and Eggett, 2000), in line with their relatively low endogenous $\mathrm{Ca}^{2+}$-buffering capacity compared to other neuronal populations (Lips and Keller, 1998; Palecek et al., 1999). In CaMII-PV transgenic mice, PV expressing motoneurons were better suited to attenuate ALS IgG-mediated increases in total calcium within motor axon terminals of interosseus muscles (Beers et al., 2001). When these mice were bred with transgenic mice expressing a mutant form of SOD1 (mSOD1), a model of familial ALS, motoneuron loss was decreased and the disease onset was delayed compared to mSOD1 mice. Kainate-induced toxicity was also better tolerated in motoneuron cultures in vitro derived from Thy-PV mice evidenced by the increased number of surviving motoneurons (Van Den Bosch et al., 2002). Dekkers et al. (in press) have demonstrated that in the same mouse strain (Thy-PV), motoneuron survival in vivo following nerve injury (crushing of the sciatic nerve) also with the likely involvement of excitotoxic effects of glutamate was significantly increased compared to control wildtype mice. All the above results demonstrate that ectopic expression of PV in motoneurons has a neuroprotective effect.

On the other hand, the extent of kainate-induced excitotoxicity (a model of mesial temporal lobe epilepsy) was not influenced by the presence of PV, CB or calretinin (CR): the extent of neuronal damage was similar in animals deficient for one or two of these proteins (Bouilleret et al., 2000). In cultures of cortical neurons using a herpes simplex virus-1 vector system containing the PV cDNA, NMDA-induced excitotoxicity was even increased, not decreased (Hartley et al., 1996). In our experiments with Thy-PV mice, we found a similar yet unexpected situation, namely, the excitotoxic damage induced by IBO was aggravated in mice ectopically expressing PV in striatal neurons. How can we reconcile such apparently contradicting results in different neuronal populations in the same mouse model?

Three possible mechanisms might be involved: (a) systems implicated in regulating $\left[\mathrm{Ca}^{2+}\right]_{\mathrm{i}}$ in a given neuron type $\left(\mathrm{Ca}^{2+}\right.$ channels or pumps, organelles involved in $\mathrm{Ca}^{2+}$ homeostasis); (b) "compensation" or "remodeling" mechanisms induced by either removal or ectopic expression of a $\mathrm{Ca}^{2+}$ buffer and (c) the biophysical parameters of the $\mathrm{Ca}^{2+}$ buffer $\left(\mathrm{Ca}^{2+}\right.$ affinity and metal-binding kinetics, mobility), but this does not need to be discussed in great detail since the expression of PV in Thy-PV mice is increased in both cases, in motoneurons and striatal neurons.

First, studies on the systems regulating $\mathrm{Ca}^{2+}$ homeostasis were carried out with the artificial fast intracellular $\mathrm{Ca}^{2+}$ buffer 1,2 bis-(2-aminophenoxy)ethane- $N, N, N^{\prime}, N^{\prime}$-tetraacetic acid (BAPTA). If present in cultured rat hippocampal neurons, BAPTA augmented rather than diminished glutamate excitotoxicity (Abdel-Hamid and Baimbridge, 1997). The authors argue that (1) the rapid $\mathrm{Ca}^{2+}$ chelating properties of BAPTA can provoke a reduction of the $\mathrm{Ca}^{2+}$ dependent inactivation of voltage-operated $\mathrm{Ca}^{2+}$ channels and NMDA-mediated $\mathrm{Ca}^{2+}$ channels and (2) BAPTA may reduce the probability of the activation of $\mathrm{Ca}^{2+}$-dependent $\mathrm{K}^{+}$channels, this all leading to an increase of total $\mathrm{Ca}^{2+}$ influx. Along the same line, hippocampal CA1 pyramidal neurons of CB-deficient knockout (KO) mice demonstrated less cellular damage following a 12-min carotid artery occlusion in vivo than the same CB-expressing neuron population of control animals (Klapstein et al., 1998). Although the $\mathrm{Ca}^{2+}$-binding kinetic of $\mathrm{PV}$ is much slower than the one of BAPTA, PV was shown to be able to reduce $\mathrm{K}^{+}$-depolarization-induced elevations of $\left[\mathrm{Ca}^{2+}\right]_{\mathrm{i}}$ in human neuroblastoma cells (Dreessen et al., 1996), while the amplitude of brief $\mathrm{Ca}^{2+}$ transients in Purkinje cell dendrites elicited by climbing fiber stimulation was not affected by PV (Schmidt et al., 2003). Similar to previous findings in PV-containing fast-twitch muscles (Schwaller et al., 1999), an increase in the initial rate of decay of $\left[\mathrm{Ca}^{2+}\right]_{\mathrm{i}}$ after a $\mathrm{Ca}^{2+}$ 
transient in Purkinje cells was attributable to the presence of PV (Schmidt et al., 2003). The presence of an additional $\mathrm{Ca}^{2+}$ buffer (PV) will not only directly affect the $\mathrm{Ca}^{2+}$ buffering capacity of the cytosol, but is likely to affect the dynamics of all systems implicated in regulating $\left[\mathrm{Ca}^{2+}\right]_{\mathrm{i}}$. That includes systems involved in $\mathrm{Ca}^{2+}$ entry and extrusion via the plasma membrane as well as those of intracellular organelles, such as the endoplasmic reticulum or mitochondria. Thus, the ectopic expression of the slow-onset buffer $\mathrm{PV}$ in all neurons as well as the elimination of PV in knockout mice could differentially affect the various components involved in $\mathrm{Ca}^{2+}$ homeostasis and alter the kinetics and the quantitative fluxes of $\mathrm{Ca}^{2+}$ ions.

Since more experiments on PV-deficient mice have been reported so far, the most pertinent findings in PV-KO mice are summarized here. As described, PV promotes a more rapid initial decay of $\left[\mathrm{Ca}^{2+}\right]_{\mathrm{i}}$ and hence, the "residual $\mathrm{Ca}^{2+}$ ", in a presynaptic terminal after stimulation will be lower than in the absence of PV. As a result, at the synapse between PV-containing stellate/basket cells and Purkinje cells, paired-pulse facilitation was increased in PV-KO mice (Caillard et al., 2000). Also in the hippocampus, facilitation of repetitive IPSCs was enhanced in the absence of PV (Vreugdenhil et al., 2003), both findings can be explained by the particular slow-onset $\mathrm{Ca}^{2+}$-binding properties of $\mathrm{PV}$. In addition, the presence of a $\mathrm{Ca}^{2+}$ buffer also affects the intracellular spreading of $\mathrm{Ca}^{2+}$ ions. Analysis of the mobility of PV in spines and dendrites of Purkinje cells has revealed that the range of action for PV-bound $\mathrm{Ca}^{2+}$ was approximately $4 \mu \mathrm{m}$ (Schmidt et al., 2003) and thus found to be very close to the value of $5 \mu \mathrm{m}$ for "buffered" $\mathrm{Ca}^{2+}$ ions reported before in the cytosol of Xenopus laevis (Allbritton et al., 1992). This distance is much larger than the $0.1 \mu \mathrm{m}$ calculated for a "free" $\mathrm{Ca}^{2+}$ ion in a cytosolic extract. Thus, due to increased diffusion of $\mathrm{Ca}^{2+}$ bound to $\mathrm{PV}, \mathrm{Ca}^{2+}$ elevations will dissipate faster and spread over larger distances than in the absence of PV. This dissipation of PV-buffered $\mathrm{Ca}^{2+}$ will diminish the $\mathrm{Ca}^{2+}$ concentration at the site of entry, usually just underneath the plasma membrane, and will increase it some distance away in proximity to intracellular organelles. By this process, $\mathrm{Ca}^{2+}$ extrusion via plasma membrane systems could be reduced, while $\mathrm{Ca}^{2+}$ sequestering by organelles is increased. This would lead to an increased $\mathrm{Ca}^{2+}$ load of these organelles with serious consequences, at least in mitochondria: at a critical $\mathrm{Ca}^{2+}$ load, mitochondria depolarize, decrease ATP synthesis, alter the synthesis of mitochondrial polypeptides and increase the generation of reactive oxygen species, leading to irreversible mitochondrial dysfunction (Krieger and Duchen, 2002).

A second factor, "remodeling", may even further enhance mitochondrial dysfunction after an excitotoxic insult: in neurons ectopically expressing $\mathrm{PV}$, the mitochondrial fractional area and thus the mitochondrial volume is reduced. The electron microscopic analyses revealed a decrease in the fractional area of mitochondria by almost $50 \%$, and the significant decrease of the COXI signal in Western blots further confirms our morphometric results. Differences in COXI signal intensities were of smaller magnitude than changes in fractional area of neuronal mitochondria, as the whole tissue homogenate used to obtain the protein fraction contains not only neurons expressing the transgene, but also glial cells, endothelial cells, etc. It has recently been shown that in PV-knockout mice, mitochondria in fast-twitch muscles are up-regulated (Chen et al., 2001), indicating that in the absence of a diffusible buffer, mitochondria contribute to $\mathrm{Ca}^{2+}$ buffering. A similar up-regulation also occurs in Purkinje cells of PV-KO mice, suggesting that a close link between PV levels and mitochondria volume is not restricted to muscle cells (B. Schwaller, in preparation). In contrast, ectopically expressed neuronal PV apparently influences mitochondrial biogenesis in the opposite direction, that is, by decreasing the mitochondrial volume, and it is tempting to speculate that mitochondrial recruitment can be influenced not only by energy metabolism, but also by its function as a $\mathrm{Ca}^{2+}$ buffer. Since the fractional volume of mitochondria must be seen in direct correlation to effectiveness of energy metabolism and capacity of transient $\mathrm{Ca}^{2+}$ storage (Nicholls and Budd, 2000), a higher probability of excitotoxin-induced neuronal death by reduced mitochondrial volume seems plausible.

Additionally, ectopical expression of PV in neurons not only increased IBO-induced neurodegeneration, but also affected the microenvironment evidenced by the larger extent of astrocytic reaction. The area of astrocytic reaction then diminished from 2 to 4 weeks to a size similar as the neuron-depleted area. In WT mice also 4 weeks after IBO injection, the size of astrocytic reaction was still larger than the neuron-depleted area. One may hypothesize that in ThyPV mice, the recovery period after IBO neurotoxicity is shorter, but mechanisms involved in this accelerated healing process are currently unknown.

The increased vulnerability of striatal neurons ectopically expressing PV to glutamate excitotoxicity as opposed to the neuroprotective effect of PV in motoneurons is an excellent example that $\mathrm{Ca}^{2+}$ buffers do not have a neuroprotective effect per se. As more knowledge is gained about the properties of the $\mathrm{Ca}^{2+}$ buffers themselves, but equally important about the properties of all systems involved in the $\mathrm{Ca}^{2+}$ homeostasis in a given cell, we start to understand why the presence of a $\mathrm{Ca}^{2+}$ buffer may be neuroprotective under certain conditions but not under others. If increasing the $\mathrm{Ca}^{2+}$-buffering capacity in selected neurons may appear useful and eventually also envisaged as a therapeutic or preventive measure, one has to keep in mind that "unwanted" remodeling mechanisms might be induced, which may have just the opposite effect than the desired one. Thus, only specifically targeted increase in $\mathrm{Ca}^{2+}$ buffering capacity, both with respect to time scale and neuron population, may be potentially used as a strategy to prevent or block certain types of excitotoxic neurodegeneration. 


\section{Acknowledgments}

The excellent technical help of Olga Bollag, Gabriela Kalt and Michaela Baeschlin is greatly appreciated. We are grateful to Drs. M. Berchtold (Inst. of Molecular Biology, University of Copenhagen, Denmark) for providing the Thy-PV mice and J. Eilers (Max-Planck-Institute for Brain Research, Frankfurt/M., Germany) for critically reading the manuscript.

\section{References}

Abdel-Hamid, K.M., Baimbridge, K.G., 1997. The effects of artificial calcium buffers on calcium responses and glutamate-mediated excitotoxicity in cultured hippocampal neurons. Neuroscience 81, 673-687.

Allbritton, N.L., Meyer, T., Stryer, L., 1992. Range of messenger action of calcium ion and inositol 1,4,5-trisphosphate. Science 258, 1812-1815.

Andra, K., Abramowski, D., Duke, M., Probst, A., Wiederhold, K.H., Burki, K., Goedert, M., Sommer, B., Staufenbiel, M., 1996. Expression of APP in transgenic mice: a comparison of neuron-specific promoters Neurobiol. Aging 17, 183-190.

Andressen, C., Blümcke, I., Celio, M.R., 1993. Calcium-binding proteins: selective markers of nerve cells. Cell Tissue Res. 271, 181-208.

Beers, D.R., Ho, B.K., Siklos, L., Alexianu, M.E., Mosier, D.R., Mohamed, A.H., Otzuka, Y., Kozovka, M.E., McAlhany, R.E., Smith, R.G., Appel, S.H., 2001. Parvalbumin overexpression alters immune-mediated increases in intracellular calcium, and delays disease onset in a transgenic model of familial amyotrophic lateral sclerosis. J. Neurochem. 79, 499-509.

Bouilleret, V., Schwaller, B., Schurmans, S., Celio, M.R., Fritschy, J.M., 2000. Neurodegenerative and morphogenic changes in a mouse model of temporal lobe epilepsy do not depend on the expression of the calcium-binding proteins parvalbumin, calbindin, or calretinin. Neuroscience $97,47-58$.

Caillard, O., Moreno, H., Schwaller, B., Llano, I., Celio, M.R., Marty, A., 2000. Role of the calcium-binding protein parvalbumin in short-term synaptic plasticity. Proc. Natl. Acad. Sci. U. S. A. 97, 13372-13377.

Capaldi, R.A., Marusich, M.F., Taanman, J.W., 1995. Mammalian cytochrome- $c$ oxidase: characterization of enzyme and immunological detection of subunits in tissue extracts and whole cells. Methods Enzymol. 260, 117-132.

Caroni, P., 1997. Overexpression of growth-associated proteins in the neurons of adult transgenic mice. J. Neurosci. Methods 71, 3-9.

Castillo, M.B., Celio, M.R., Andressen, C., Gotzos, V., Rulicke, T., Berger, M.C., Weber, J., Berchtold, M.W., 1995. Production and analysis of transgenic mice with ectopic expression of parvalbumin. Arch. Biochem. Biophys. 317, 292-298.

Celio, M.R., 1990. Calbindin D-28k and parvalbumin in the rat nervous system. Neuroscience 35, 375-475.

Chen, G., Carroll, S., Racay, P., Dick, J., Pette, D., Traub, I., Vrbova, G., Eggli, P., Celio, M., Schwaller, B., 2001. Deficiency in parvalbumin increases fatigue resistance in fast-twitch muscle and upregulates mitochondria. Am. J. Physiol. Cell Physiol. 281, C114-C122.

Choi, D.W., 1988. Calcium-mediated neurotoxicity: relationship to specific channel types and role in ischemic damage. Trends Neurosci. 11, $465-469$.

Choi, D.W., 1995. Calcium: still center-stage in hypoxic-ischemic neuronal death. Trends Neurosci. 18, 58-60.

Dekkers, J., Bayley, P., Dick, J., Schwaller, B., Berchtold, M.W., Greensmith, L., 2004. Effect of neonatal nerve injury on motoneurone survival and function in parvalbumin-overexpressing transgenic mice. Neuroscience (in press).

DiFiglia, M., 1990. Excitotoxic injury of the neostriatum: a model for Huntington's disease. Trends Neurosci. 13, 286-289.
Dirnagl, U., Iadecola, C., Moskowitz, M.A., 1999. Pathobiology of ischaemic stroke: an integrated view. Trends Neurosci. 22, 391-397.

D’Orlando, C., Felley, B., Schwaller, B., Salicio, V., Bloc, A., Gotzos, V., Celio, M.R., 2001. Calretinin and calbindin D-28k delay the onset of cell death after excitotoxic stimulation in transfected P19 cells. Brain Res. 909, 145-158.

D'Orlando, C., Celio, M.R., Schwaller, B., 2002. Calretinin and calbindin D-28k, but not parvalbumin protect against glutamate-induced excitotoxicity in transfected N18-RE 105 neuroblastoma-retina hybrid cells. Brain Res. 945, 181-190.

Dreessen, J., Lutum, C., Schafer, B.W., Heizmann, C.W., Knopfel, T., 1996. Alpha-parvalbumin reduces depolarization-induced elevations of cytosolic free calcium in human neuroblastoma cells. Cell Calcium $19,527-533$

Dusart, I., Marty, S., Peschanski, M., 1991. Glial changes following an excitotoxic lesion in the CNS-II. Astrocytes. Neuroscience 45, $541-549$.

Franklin, K.B.J., Paxinos, G., 1997. The Mouse Brain in Stereotaxic Coordinates. Academic press, San Diego.

Hartley, D.M., Neve, R.L., Bryan, J., Ullrey, D.B., Bak, S.Y., Lang, P., Geller, A.I., 1996. Expression of the calcium-binding protein, parvalbumin, in cultured cortical neurons using a HSV-1 vector system enhances NMDA neurotoxicity. Mol. Brain Res. 40, 285-296.

Heizmann, C.W., Braun, K., 1992. Changes in $\mathrm{Ca}(2+)$-binding proteins in human neurodegenerative disorders. Trends Neurosci. 15, 259-264.

Hontanilla, B., Parent, A., Heras, S., Gimenez-Amaya, J.M., 1998. Distribution of calbindin D-28k and parvalbumin neurons and fibers in the rat basal ganglia. Brain Res. Bull. 47, 107-116.

Hossmann, K.A., 1994. Glutamate-mediated injury in focal cerebral ischemia: the excitotoxin hypothesis revised. Brain Pathol. 4, 23-36.

Inglis, W.L., Semba, K., 1997. Discriminable excitotoxic effects of ibotenic acid, AMPA, NMDA and quinolinic acid in the rat laterodorsal tegmental nucleus. Brain Res. 755, 17-27.

Kita, H., Kosaka, T., Heizmann, C.W., 1990. Parvalbumin-immunoreactive neurons in the rat neostriatum: a light and electron microscopic study. Brain Res. 536, 1-15.

Klapstein, G.J., Viela, S., Lieberman, D.N., Gray, P.A., Airaksinen, M.S., Thoenen, H., Meyer, M., Mody, I., 1998. Calbindin-D28k fails to protect hippocampal neurons against ischemia in spite of its cytoplasmic calcium buffering properties: evidence from calbindin-D28k knockout mice. Neuroscience 85, 361-373.

Krieger, C., Duchen, M.R., 2002. Mitochondria, $\mathrm{Ca}(2+)$ and neurodegenerative disease. Eur. J. Pharmacol. 447, 177-188.

Lee, J.M., Zipfel, G.J., Choi, D.W., 1999. The changing landscape of ischaemic brain injury mechanisms. Nature 399 (6738 Suppl.), A7-A14.

Lips, M.B., Keller, B.U., 1998. Endogenous calcium buffering in motoneurones of the nucleus hypoglossus from mouse. J. Physiol. (London) $511,105-117$.

Lipton, S.A., Rosenberg, P.A., 1994. Excitatory amino acids as a final common pathway for neurologic disorders. N. Engl. J. Med. 330, 613-622.

Marret, S., Gressens, P., Evrard, P., 1996. Arrest of neuronal migration by excitatory amino acids in hamster developing brain. Proc. Natl. Acad. Sci. U. S. A. $93,15463-15468$.

Nicholls, D.G., Budd, S.L., 2000. Mitochondria and neuronal survival. Phys. Rev. 80, 315-360.

Nitsch, C., Scotti, A., Sommacal, A., Kalt, G., 1989. GABAergic hippocampal neurons resistant to ischemia-induced neuronal death contain the Ca2(+)-binding protein parvalbumin. Neurosci. Lett. 105, 263-268.

Nitsch, C., Scotti, A.L., Nitsch, F.M., 1995. Distribution of parvalbumincontaining interneurons in the hippocampus of the gerbil-A qualitative and quantitative statistical analysis. J. Chem. Neuroanat. 9, 135-147.

Palecek, J., Lips, M.B., Keller, B.U., 1999. Calcium dynamics and buffering in motoneurones of the mouse spinal cord. J. Physiol. 520 (Pt 2), $485-502$.

Schinder, A.F., Olson, E.cC., Spitzer, N.C., Montal, M., 1996. Mitochondrial dysfunction is a primary event in glutamate neurotoxicity. J. Neurosci. $16,6125-6133$. 
Schmidt, H., Brown, E.B., Schwaller, B., Eilers, J., 2003. Diffusional mobility of parvalbumin in spiny dendrites of cerebellar Purkinje neurons quantified by fluorescence recovery after photobleaching. Biophys. J. 84, 2599-2608.

Schwaller, B., Dick, J., Dhoot, G., Carroll, S., Vrbova, G., Nicotera, P., Pette, D., Wyss, A., Bluethmann, H., Hunziker, W., Celio, M.R., 1999. Prolonged contraction-relaxation cycle of fast-twitch muscles in parvalbumin knockout mice. Am. J. Physiol. 276, C395-C403.

Schwaller, B., Meyer, M., Schiffmann, S.N., 2002. "New" functions for "old" proteins: the role of the calcium-binding proteins calbindin D$28 \mathrm{k}$, calretinin and parvalbumin, in cerebellar physiology. Studies with knockout mice. The Cerebellum 1, 241-258.

Schwarcz, R., Hökfelt, T., Fuxe, K., Jonsson, G., Goldstein, M., Terenius, L., 1979. Ibotenic acid-induced neuronal degeneration: a morphological and neurochemical study. Exp. Brain Res. 37, 199-216.

Shaw, P.J., Eggett, C.T., 2000. Molecular factors underlying selective vulnerability of motor neurons to neurodegeneration in amyotrophic lateral sclerosis. J. Neurol. 247, I17-I27.

Simon, R.P., Swan, J.H., Griffiths, T., Meldrum, B.S., 1984. Blockade of $\mathrm{N}$-methyl-D-aspartate receptors may protect against ischemic damage in the brain. Science 226, 850-852.

Sloviter, R.S., Sollas, A.L., Barbaro, N.M., Laxer, K.D., 1991. Calciumbinding protein (calbindin-D28K) and parvalbumin immunocytochemistry in the normal and epileptic human hippocampus. J. Comp. Neurol. 308, 381-396.

Solodkin, A., Veldhuizen, S.D., Van Hoesen, G.W., 1996. Contingent vul- nerability of entorhinal parvalbumin-containing neurons in Alzheimer's disease. J. Neurosci. 16, 3311-3321.

Turski, L., Huth, A., Sheardown, M., McDonald, F., Neuhaus, R., Schneider, H.H., Dirnagl, U., Wiegand, F., Jacobsen, P., Ottow, E., 1998. ZK200775: a phosphonate quinoxalinedione AMPA antagonist for neuroprotection in stroke and trauma. Proc. Natl. Acad. Sci. U. S. A. 95, 10960-10965.

Van Den Bosch, L., Schwaller, B., Vleminckx, V., Meijers, B., Stork, S., Ruehlicke, T., Van Houtte, E., Klaassen, H., Celio, M.R., Missiaen, L., Robberecht, W., Berchtold, M.W., 2002. Protective effect of parvalbumin on excitotoxic motor neuron death. Exp. Neurol. 174, 150-161.

Vreugdenhil, M., Jefferys, J.G.R., Celio, M.R., Schwaller, B., 2003. Parvalbumin-deficiency facilitates repetitive IPSCs and related inhibitionbased gamma oscillations in the hippocampus. J. Neurophysiol. 89, $1414-1423$.

Weiss, J.H., Sensi, S.L., 2000. $\mathrm{Ca}^{2+}-\mathrm{Zn}^{2+}$ permeable AMPA or kainate receptors: possible key factors in selective neurodegeneration. Trends Neurosci. 23, 365-371.

Wisden, W., Cope, D., Klausberger, T., Hauer, B., Sinkkonen, S.T., Tretter, V., Lujan, R., Jones, A., Korpi, E.R., Mody, I., Sieghart, W. Somogyi, P., 2002. Ectopic expression of the GABA(A) receptor alpha6 subunit in hippocampal pyramidal neurons produces extrasynaptic receptors and an increased tonic inhibition. Neuropharmacology 43 , $530-549$.

Zorumski, C.F., Todd, R.D., Clifford, D.B., 1989. Complex responses activated by ibotenate in postnatal rat hippocampal neurons. Brain Res. 494, 193-197. 